\title{
Two Cases of Stress Cardiomyopathy during Esophagogastroduodenoscopy
}

\author{
Jong Won Yu, Jongha Park, Pil Sang Song, Jae Hyun Park, Min Sung Kim, Gi Jung Jeon, Min Sik Kim and Tae Oh Kim \\ Department of Internal Medicine, Inje University Haeundae Paik Hospital, Inje University College of Medicine, Busan, Korea
}

Esophagogastroduodenoscopy (EGD) is considered a relatively safe procedure. However, the procedure and the materials used in EGD with conscious sedation can cause stress to the patient. Adverse events during EGD have been reported, represented by cardiopulmonary complications. To date, five cases have reported worldwide to be associated with gastrointestinal endoscopy. Stress cardiomyopathy (SCMP) is a reversible cardiomyopathy that typically occurs in postmenopausal women due to stress and may resolve within a few weeks. SCMP resembles acute myocardial infarction but differs in terms of treatment and prognosis. Here, we describe two cases of SCMP with shock during EGD with conscious sedation. Clin Endosc 2016;49:76-80

Key Words: Takotsubo cardiomyopathy; Endoscopy, digestive system; Reversible cardiomyopathy

\section{INTRODUCTION}

In general, esophagogastroduodenoscopy (EGD) is considered a relatively safe procedure. ${ }^{1}$ However, during EGD, some adverse events such as heart failure and acute myocardial infarction (MI) may occur. ${ }^{1}$ As far as we know, only five cases of stress cardiomyopathy (SCMP) have been reported in association with gastrointestinal endoscopy. ${ }^{2}$ SCMP is a reversible cardiomyopathy that typically occurs in postmenopausal elderly women due to stress, and may resolve within a few weeks. ${ }^{3}$ Here, we describe two cases of SCMP with shock during EGD with conscious sedation.

Received: February 2, 2015 Accepted: April 6, 2015

Correspondence: Jongha Park

Department of Internal Medicine, Inje University Haeundae Paik Hospital, Inje University College of Medicine, 875 Haeun-daero, Haeundae-gu, Busan 48108, Korea

Tel: +82-51-797-0200, Fax: +82-51-797-0200, E-mail: H00095@paik.ac.kr

(cc) This is an Open Access article distributed under the terms of the Creative Commons Attribution Non-Commercial License (http://creativecommons.org/ licenses/by-nc/3.0) which permits unrestricted non-commercial use, distribution, and reproduction in any medium, provided the original work is properly cited.

\section{CASE REPORTS}

\section{Case 1}

A 44-year-old woman with no relevant medical history underwent EGD for screening in late July 2014. She had previously undergone two EGDs without any complication. Her vital signs before the EGD were normal (blood pressure [BP] $110 / 70 \mathrm{~mm} \mathrm{Hg}$, pulse rate [PR] 84 beats per minute). Her electrocardiography (ECG) patterns and saturation of peripheral oxygen $\left(\mathrm{SpO}_{2}\right)$ were normal. No signs of pain or discomfort were observed before the insertion of the EGD scope. For the EGD, lidocaine hydrochloride (20 mg spray) was administered to the throat, and $5 \mathrm{mg}$ midazolam administered intravenously (IV) was used as a sedative. After the EGD scope was inserted through the pyriform sinus into the esophagus, however, she suddenly complained of chest discomfort and dyspnea. Her BP and PR increased to $180 / 160 \mathrm{~mm} \mathrm{Hg}$ and 164 beats per minute, respectively. To awaken her from the sedation state, $0.25 \mathrm{mg}$ flumazenil was immediately administered IV to reverse the effect of the sedative, and the EGD was stopped. She was moved to the emergency room (ER) for the evaluation of chest discomfort and dyspnea. Her 12lead ECG showed ST elevation in the I and aVL leads, and II, III, aVF, and V4-6 ST depression in the ER (Fig. 1A). After 20 

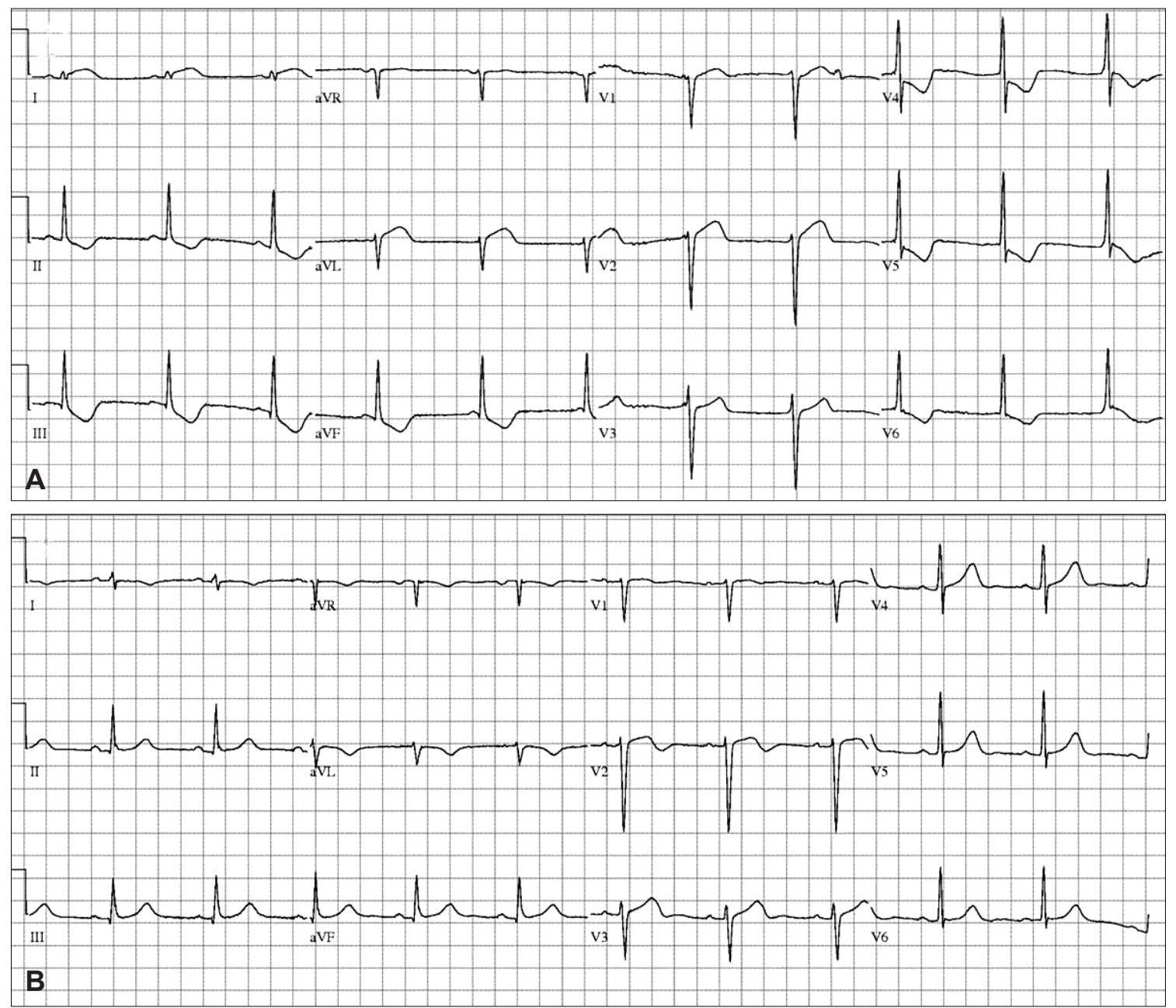

Fig. 1. Electrocardiography (ECG). (A) ECG shows ST elevation in the I and aVL leads, and ST depression in the II, III, aVF, V4 to 6, (B) ST elevation and ST depression improvement.

minutes, her BP was $62 / 24 \mathrm{~mm} \mathrm{Hg}$, PR was 67 beats per minute, $\mathrm{SpO}_{2}$ was $99 \%$ under nasal $\mathrm{O}_{2}(2 \mathrm{~L})$, and respiration rate was 20 breaths per minute. As her BP was below $90 / 60 \mathrm{~mm}$ $\mathrm{Hg}, 2 \mathrm{~L}$ normal saline was administered IV and a vasoactive agent, norepinephrine, was started. The initial level of cardiac enzyme was normal. After several hours, her cardiac enzyme level increased: creatine phosphokinase MB (CK-MB) 19.1 $\mathrm{ng} / \mathrm{mL}$ (reference range, 0.6 to 6.3 ) and troponin I (Tn-I) 5.39 $\mathrm{ng} / \mathrm{mL}$ (reference range, 0 to 0.5 ). The transthoracic echocardiogram (TTE) showed only a hypokinetic mid-left ventricle with an ejection fraction (EF) of 58\% (Fig. 2).

The first impression was ST elevation MI. Cardiac catheterization was carried out, but the result was normal. Also, the left ventriculogram showed a hypokinetic mid-left ventricle (Fig. 3)

Finally, SCMP was diagnosed and she underwent conservative treatment. Two days after EGD, her cardiac enzyme levels returned to normal. Three days after $\mathrm{EGD}$, her $\mathrm{SpO}_{2}$ was $>95 \%$ with room air and her ECG returned to normal (Fig. 1B). Her chest discomfort and dyspnea were resolved. The next day, the low BP recovered without a vasoactive agent. She fully recovered without other special events and then was discharged.

\section{Case 2}

A 45-year-old-woman underwent EGD for the follow-up of gastric gastrointestinal stromal tumor (GIST) in late April 2014. In the previous year, she underwent EGD with conscious sedation and endoscopic ultrasonography without any complication. She had no relevant medical history except for gastric GIST. Her vital signs, ECG pattern, and $\mathrm{SpO}_{2}$ before the EGD were all normal. For the EGD, lidocaine hydrochloride (20 $\mathrm{mg}$ spray) was administered to the throat, and $5 \mathrm{mg}$ midazolam IV was used as a sedative. One minute after the insertion of the EGD scope, she suddenly complained of chest discomfort. Her $\mathrm{BP}$ and $\mathrm{SpO}_{2}$ decreased to $75 / 50 \mathrm{~mm} \mathrm{Hg}$ and $80 \%$, respectively, and heart rate (HR) increased to $120 / \mathrm{min}$. 


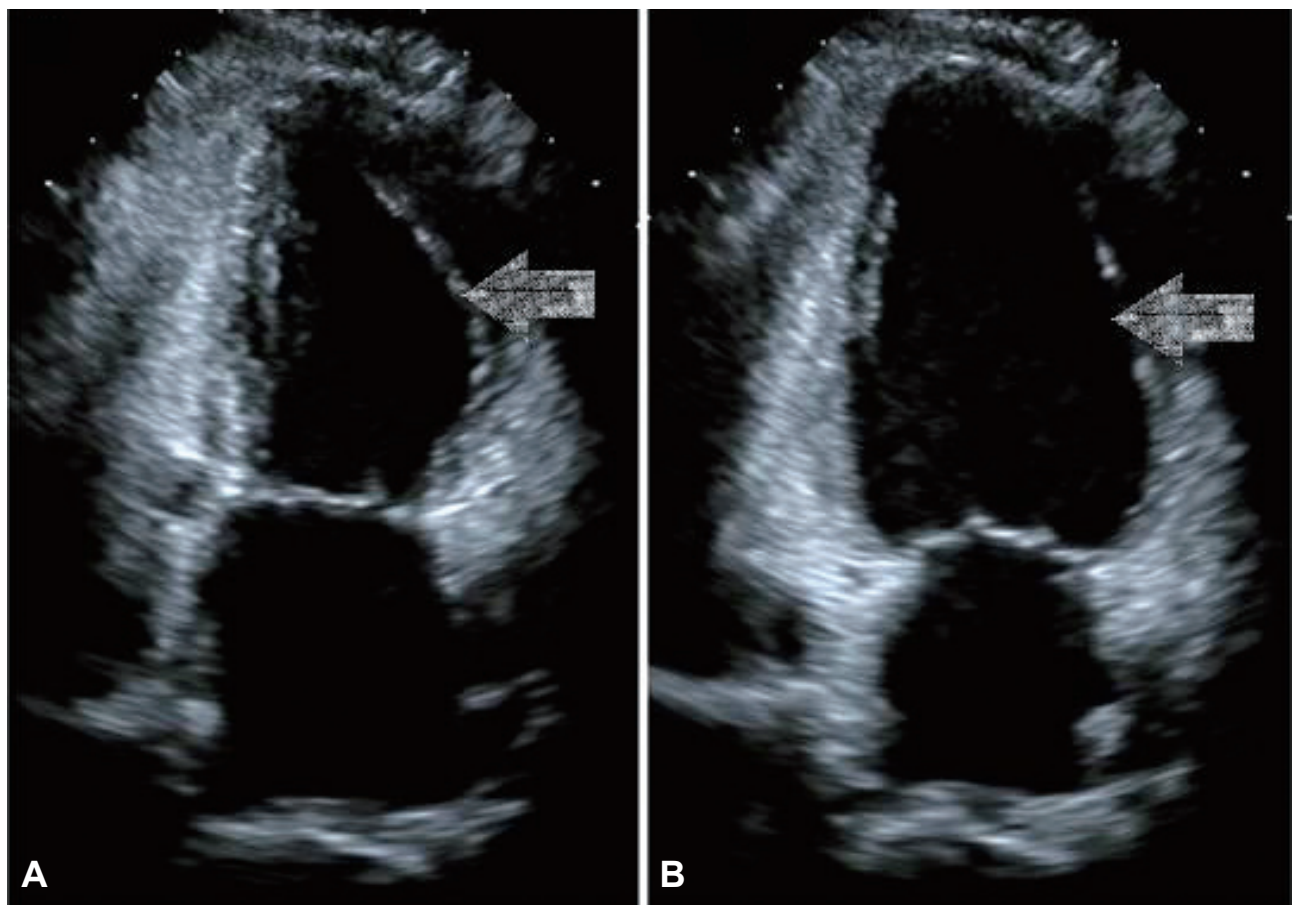

Fig. 2. Transthoracic echocardiography (TTE). TTE shows hypokinetic mid left ventricle in (arrows) (A) systole and (B) diastole.
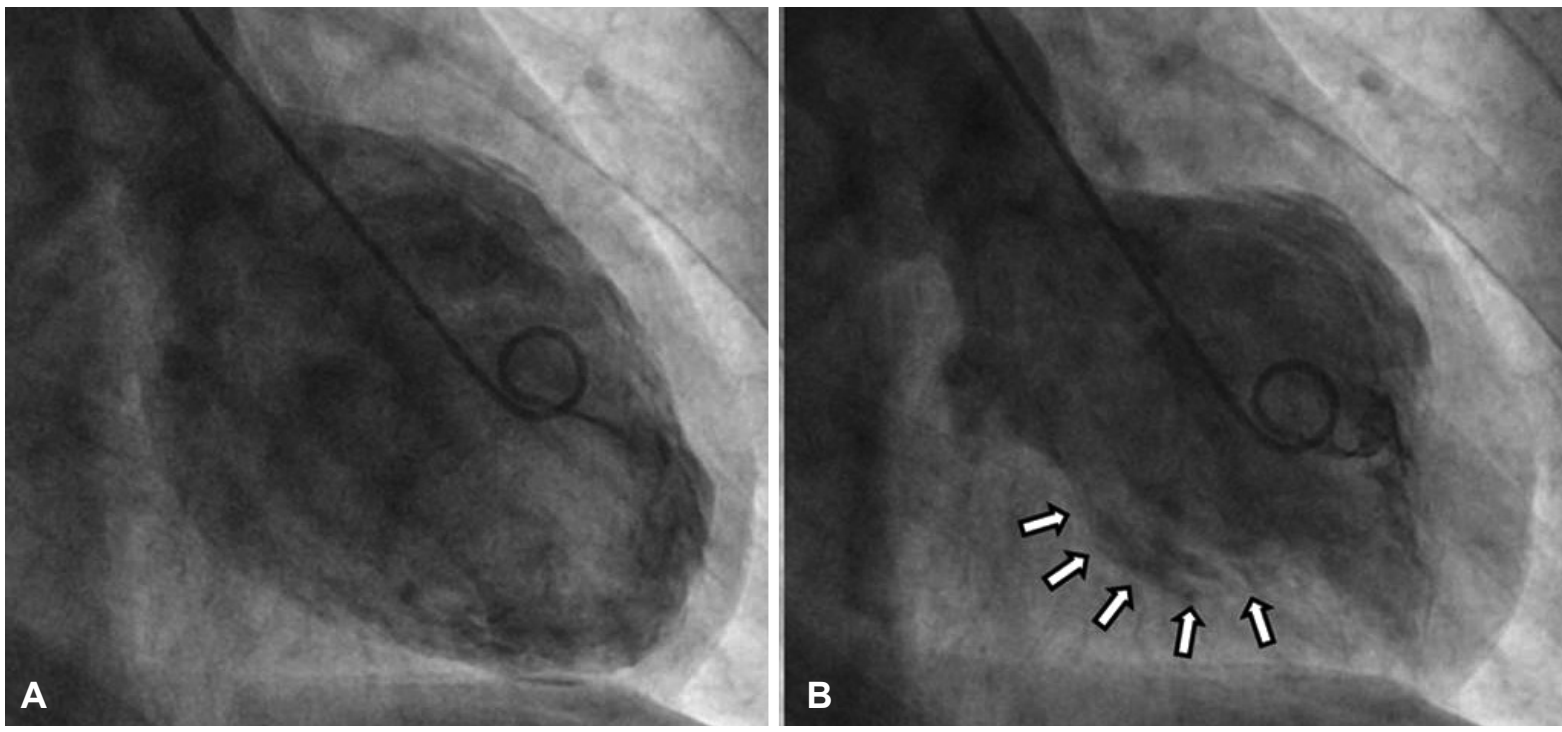

Fig. 3. Left ventriculogram. Left ventriculogram shows hypokinetic mid left ventricle in (A) diastole and (B) systole (arrows).

To reverse the effect of the sedative, $0.25 \mathrm{mg}$ flumazenil was administered IV and the EGD was stopped. After the withdrawal of the EGD scope, she spat out fresh blood with cough. After supplying $10 \mathrm{~L} \mathrm{O}_{2}$ through a reservoir mask, her $\mathrm{SpO}_{2}$ was $90 \%$ to $91 \%$. Normal saline $(500 \mathrm{~mL})$ was administered IV, and her systolic BP was $90 \mathrm{~mm} \mathrm{Hg}$. She was moved to the ER for the evaluation of chest discomfort, dyspnea, hemoptysis, and shock. Her ECG was normal; however, the cardiac enzyme levels were elevated: CK-MB $11.3 \mathrm{ng} / \mathrm{mL}$ and $\mathrm{Tn}-\mathrm{I} 3.79$ $\mathrm{ng} / \mathrm{mL}$. Chest computed tomography (CT) showed a multiple ground-glass opacity pattern and interlobular thickening, and the impression was pulmonary edema. TTE showed only a hypokinetic mid-left ventricle, with an ejection flow of $45 \%$. To rule out MI, coronary artery CT was carried out and the result was normal. Moreover, the evaluation for pheochromocytoma-measurement of metanephrine and catecholamine in plasma and through a 24-hour urine collection-was performed, and the results were in the normal range. 
Finally, SCMP was diagnosed and she underwent conservative treatment. One day after EGD, her $\mathrm{SpO}_{2}$ was $>95 \%$ with room air. Two days after EGD, her chest discomfort, dyspnea, and hemoptysis were resolved. Three days after EGD, the elevated cardiac enzymes returned to normal levels. Six days after EGD, the follow-up TTE showed no abnormal contraction with an EF of 66\%. Seven days after EGD, she had fully recovered without adverse events and then discharged.

\section{DISCUSSION}

EGD is relatively safe procedure that has been widely performed. ${ }^{1}$ However, patients may usually experience anxiety and a feeling of discomfort when undergoing the procedure. Conscious sedation is associated with patient tolerance of and satisfaction with EGD; thus, EGD is mainly performed under conscious sedation. During the practice of EGD, undesirable complications may occur. ${ }^{1}$ In a prospective study of 14,149 EGD cases, prompt cardiopulmonary incidents occurred in 2 per 1,000 cases. The 30-day mortality rate was 1 per 2,000 cases. ${ }^{1}$ In another retrospective study of 21,011 EGD cases, cardiopulmonary complication occurred in 5.4 per 1,000 cases. $^{1}$

Acute MI is similar in clinical features to SCMP, as observed in our cases. SCMP is a cardiomyopathy that is a reversible left ventricular contraction failure caused by acute stress, without coronary artery disease and mainly occurring in postmenopausal elderly women. ${ }^{3-6}$ In most cases, SCMP could be improved in a few weeks but could rarely cause pulmonary edema, cardiogenic shock, arrhythmias, heart failure, or death. ${ }^{5,7}$ Therefore, SCMP should be distinguished from $\mathrm{MI}$ owing to the differences in treatment and prognosis. The current diagnostic criteria for SCMP have recently been published (Table 1). ${ }^{7}$ There are a few hypotheses about the etiology of SCMP: emotional stress, certain pharmacologic agents, exogenous catecholamine, and unstable condition of autonomic nervous system. ${ }^{8}$ Stress factors such as the EGD procedure and sedatives may induce an unstable auto- nomic nervous condition. Insertion of the EGD scope from the pharynx into the esophagus, and from the lower esophagus to the cardia of the stomach, may induce tachycardia as a result of sympathetic nervous system hyperactivity. ${ }^{9}$ The unstable condition of the autonomic nervous system due to EGD might have played a critical role in the development of SCMP in our cases. In one of our cases, during EGD insertion from the pharynx to the esophagus, the patient's HR increased to $164 / \mathrm{mm}$ and she experienced chest pain and dyspnea. Globally, only five cases of SCMP associated with gastrointestinal endoscopy have been reported. Previous reports indicated one case of EGD in a postmenopausal woman with sedation, three cases of colonoscopy, and one case of simultaneous EGD and colonoscopy in a postmenopausal woman. $^{2,9,10}$

Compared with previous cases, our patients were premenopausal women without drug allergy, medication history, and cardiopulmonary disease, who had undergone several EGD procedures under conscious sedation. The SCMP in our patients is a rare cardiomyopathy but could occur during medical procedures such as EGD. Therefore, clinicians should know that SCMP could occur during EGD .

For the prevention and management of SCMP, assessment of cardiopulmonary status during the EGD, as well as a review of current drug use and drug allergies and physical examination of the patient should be performed. ${ }^{1}$ Supplemental oxygen supply was reported to reduce the magnitude of oxygen desaturation. ${ }^{11}$ Continuous ECG monitoring is appropriate in high-risk patients, in those with significant cardiopulmonary disease, in elderly patients, and when the procedure is expected to be long. ${ }^{1}$ Capnography can be used to monitor the patient's respiratory activity. ${ }^{12}$

Furthermore, proper selection of sedatives and dosage is needed. The commonly used sedatives are benzodiazepines. Most endoscopists favor midazolam for its fast onset, short duration of action, and high amnestic properties. The usual total dose is 2.5 to $5 \mathrm{mg}$. Lower doses may be used in the elderly or in patients taking other central nervous system depressants. $^{1}$

Table 1. Proposed Mayo Clinic Criteria for the Diagnosis of Takotsubo Cardiomyopathy and Long Term Prognosis

\footnotetext{
Mayo-clinic diagnostic criteria

1. Transient hypokinesis, akinesis, or dyskinesis of the left ventricular mid segments with or without apical involvement; the regional wall motion abnormalities extend beyond a single epicardial vascular distribution; a stressful trigger is often, but not always, present ${ }^{\text {a) }}$

2. Absence of obstructive coronary disease or angiographic evidence of acute plaque rupture ${ }^{b)}$

3. New electrocardiographic abnormalities (either ST-segment elevation and/or T-wave inversion) or modest elevation in cardiac troponin

4. Absence of: pheochromocytoma, myocarditis

a) There are rare exceptions to these criteria such as those patients in whom the regional wall motion abnormality is limited to a single coronary territory; ${ }^{\text {b) }}$ It is possible that a patient with obstructive coronary atherosclerosis may also develop takotsubo cardiomyopathy. However, this is very rare in our experience as well as in the published literature, perhaps because such cases are misdiagnosed as an acute coronary syndrome.
} 
In conclusion, physicians should be aware that SCMP could occur during EGD. For the risk minimization and management of SCMP during EGD with conscious sedation, assessment of the patient's cardiopulmonary status, review of current drugs, and physical examination before EGD should be carried out, as well as continuous ECG monitoring and pulse oximetry with or without capnography in high-risk patients. Moreover, an appropriate titration dose of the sedative should be used depending on the patient's risk.

\section{Conflicts of Interest}

The authors have no financial conflicts of interest.

\section{REFERENCES}

1. Waring JP, Baron TH, Hirota WK, et al. Guidelines for conscious sedation and monitoring during gastrointestinal endoscopy. Gastrointest Endosc 2003;58:317-322

2. Kim SR, Nakashima K, Nishiuchi S, et al. A case of takotsubo cardiomyopathy with ventricular fibrillation after gastroenterological endoscopy. Clin J Gastroenterol 2011;4:73-78.

3. Kawai S, Kitabatake A, Tomoike H; Takotsubo Cardiomyopathy Group. Guidelines for diagnosis of takotsubo (ampulla) cardiomyopathy. Circ J 2007;71:990-992.
4. Bybee KA, Prasad A. Stress-related cardiomyopathy syndromes. Circulation 2008;118:397-409.

5. Gianni M, Dentali F, Grandi AM, Sumner G, Hiralal R, Lonn E. Apical ballooning syndrome or takotsubo cardiomyopathy: a systematic review. Eur Heart J 2006;27:1523-1529.

6. Park JH, Kang SJ, Song JK, et al. Left ventricular apical ballooning due to severe physical stress in patients admitted to the medical ICU. Chest 2005;128:296-302.

7. Madhavan M, Prasad A. Proposed Mayo Clinic criteria for the diagnosis of Tako-Tsubo cardiomyopathy and long-term prognosis. Herz 2010;35:240-243

8. Sharkey SW, Windenburg DC, Lesser JR, et al. Natural history and expansive clinical profile of stress (tako-tsubo) cardiomyopathy. J Am Coll Cardiol 2010;55:333-341.

9. Akashi R, Oogushi M, Yoshida M, et al. A case report of "takotsubo"type cardiomyophaty during upper digestive endoscopy. Gastroenterol Endosc 2003;45:253-260.

10. Kaneko E, Harada H, Kasugai T, Ogoshi K, Tanba H. Complications from gastrointestinal endoscopy procedure from 1998 to 2002. Gastroenterol Endosc 2004;46:54-61.

11. Bell GD, Bown S, Morden A, Coady T, Logan RF. Prevention of hypoxaemia during upper-gastrointestinal endoscopy by means of oxygen via nasal cannulae. Lancet 1987;1:1022-1024.

12. Vargo JJ, Zuccaro G Jr, Dumot JA, Conwell DL, Morrow JB, Shay SS. Automated graphic assessment of respiratory activity is superior to pulse oximetry and visual assessment for the detection of early respiratory depression during therapeutic upper endoscopy. Gastrointest Endosc 2002;55:826-831. 